\title{
Platelet-activating factor levels of serum and gingival crevicular fluid in nonsmoking patients with periodontitis and/or coronary heart disease
}

\author{
Hui Chen • Pei Zheng • Haihua Zhu • Jianhua Zhu • \\ Lili Zhao • Nour Eddine El Mokhtari • Jörg Eberhard • \\ Markus Lins • Søren Jepsen
}

Received: 28 July 2009 / Accepted: 22 September 2009/Published online: 14 October 2009

(C) Springer-Verlag 2009

\begin{abstract}
The purpose of the present study was to investigate systemic and local levels of platelet-activating factor (PAF), a potent proinflammatory mediator implicated in cardiovascular pathophysiology in adult nonsmoking patients with periodontitis with or without coronary heart disease (CHD). Eighty-seven volunteers, 25 periodontitis patients, 19 periodontitis with CHD patients, 19 CHD patients, and 24 healthy controls were included, and periodontal conditions were assessed. Gingival crevicular fluid (GCF) and venous blood were collected, and PAF levels were measured by enzymelinked immunosorbent assay. PAF levels in serum (303.3 \pm $204 \mathrm{pg} / \mathrm{ml})$ and in GCF $(26.3 \pm 6 \mathrm{pg} / \mu \mathrm{l})$ of the periodontitis
\end{abstract}

Markus Lins and Søren Jepsen share senior authorship.

H. Chen $\cdot$ P. Zheng $\cdot$ H. Zhu

Department of Conservative Dentistry and Periodontics, Affiliated Hospital of Stomatology, Medical College, Zhejiang University,

Hangzhou, People's Republic of China

J. Zhu $\cdot$ L. Zhao

Department of Cardiology, Medical College, Zhejiang University, Hangzhou, People's Republic of China

N. E. El Mokhtari $\cdot$ M. Lins

Department of Cardiology,

University Hospital Schleswig-Holstein, Campus Kiel,

Kiel, Germany

J. Eberhard

Department of Preventive Dentistry, Periodontology

and Cariology, University of Göttingen,

Göttingen, Germany

\section{S. Jepsen $(\bowtie)$}

Department of Periodontology, Operative and Preventive

Dentistry, University of Bonn,

Welschnonnenstr, 17,

53111 Bonn, Germany

e-mail: jepsen@uni-bonn.de group with $\mathrm{CHD}$, the periodontitis group (serum, 302.4 \pm $241 \mathrm{pg} / \mathrm{ml}$ and GCF, $26.3 \pm 8 \mathrm{pg} / \mu \mathrm{l}$ ) and the CHD group (serum, $284.7 \pm 192 \mathrm{pg} / \mathrm{ml}$ and GCF, $20.8 \pm 6 \mathrm{pg} / \mu \mathrm{l}$ ) were significantly higher than the healthy control group (serum, $65.4 \pm 35 \mathrm{pg} / \mathrm{ml}$ and GCF, $7.7 \pm 3 \mathrm{pg} / \mu \mathrm{l} ; p<0.05$ ). In summary, the present study could demonstrate that in patients with periodontitis, the inflammatory mediator PAF is released into serum at least in the same range as for patients with coronary heart disease. However, no additive effects were seen when both conditions were present.

Keywords Oral inflammation · Systemic effects · Plateletactivating factor $\cdot$ Periodontitis $\cdot$ Coronary heart disease

\section{Introduction}

A series of genetic and environmental risk factors such as hypertension, hypercholesterolemia, dyslipidemia, obesity, diabetes mellitus, and smoking are well-established risk factors for atherosclerotic cardiovascular diseases [1]. During the past 15 years, the hypothesis was raised that chronic infections may contribute to the development of atherosclerosis $[2,3]$. Published data have also shown that oral inflammation and periodontal disease in particular could increase the risk for coronary heart disease (CHD) [4-7]. However, the pathways by which inflammatory processes may contribute to cardiovascular disease are still unclear [8].

Platelet-activating factor (PAF) is one of the most potent and versatile proinflammatory mediators found in mammals [9]. It can be produced and released from a variety of cells, especially activated inflammatory cells such as macrophages, thrombocytes, and lymphocytes [10]. PAF pro- 
motes the aggregation, chemotaxis, granule secretion, and oxygen radical generation from leukocytes and the adherence of leukocytes to endothelium [11, 12]. PAF increases the permeability of endothelial cell monolayers and stimulates the contraction of smooth muscle [10]. These physiological activities of PAF support the hypothesis that PAF may play a role in the initiation and progression of CHD [13-15]. Clinical animal studies have shown higher levels of PAF in coronary artery samples from animals with severe atherosclerosis compared to healthy controls [16].

Since the presence of PAF in human mixed saliva was first reported, only a few studies have tried to reveal the relationship between PAF and periodontal inflammation $[17,18]$. It has been demonstrated that PAF released by inflamed periodontal tissues could be measured within the gingival sulcus fluid [18] and was reduced after periodontal therapy [19]. In a previous study of our group, a significant positive correlation was observed between periodontal parameters and the levels of PAF in both serum and gingival crevicular fluid (GCF) from patients suffering from periodontitis [20]. The detection of this metabolite in blood from patients suffering from periodontitis is a precondition for a possible molecular link between the lipid mediator PAF originating from inflamed periodontal tissues and the development of CHD.

We have previously shown that periodontitis is associated with elevated systemic levels of the inflammatory mediator PAF, which is implicated in the pathopysiology of coronary heart disease and hypothesize that additive or synergistic effects on PAF serum levels might be found if both conditions are present. Therefore, the purpose of the present study was to investigate local and systemic PAF levels in adult patients with periodontitis, with our without concomitant coronary heart disease in comparison to healthy individuals.

\section{Methods}

\section{Study population}

A total of 87 nonsmoking subjects were recruited from the School of Medicine, Zhejiang University, China into the study (Table 1). Thirty-eight patients with proven CHD were treated between December 1999 and June 2005. All patients with CHD had suffered from a recent history of severe angina pectoris symptoms (less than 6 months prior to the study) as verified by hospitalization and a significant diameter stenosis of at least $50 \%$ in one or more coronary arteries, diagnosed by coronary angiography. In addition, a group of 49 subjects, presenting with or without periodontitis, participated in this study. Informed consent was obtained from all patients, and the study was approved by
Table 1 Age and gender of the investigated groups

\begin{tabular}{lllll}
\hline Group & Gender & Number & \multicolumn{2}{l}{ Age (years) } \\
\cline { 3 - 5 } & & & Mean & SD \\
\hline Perio + CHD & male & 13 & 48.50 & 3.20 \\
& female & 6 & 48.00 & 2.50 \\
Perio & male & 12 & 39.20 & 5.30 \\
& female & 13 & 40.50 & 8.50 \\
CHD & male & 12 & 44.90 & 3.80 \\
& female & 7 & 42.40 & 2.30 \\
Healthy & male & 10 & 32.90 & 6.40 \\
& female & 14 & 38.70 & 7.50 \\
\hline
\end{tabular}

the Ethics Committee of Zhejiang University. The same examiner conducted all periodontal assessments.

All subjects were classified into four groups:

Periodontitis group (Perio) Twenty-five subjects (13 females, 12 males; age, 23-52 years) with proven periodontitis. Patients were classified based on the clinical examination including periodontal probing depth $\geq 4 \mathrm{~mm}$, bleeding on probing, and an attachment loss $\geq 2 \mathrm{~mm}$ of at least four teeth, as well as radiographic evidence of bone loss.

Coronary heart disease group (CHD) Nineteen subjects (seven females, 12 males; age, 38-50 years) with proven CHD, but no signs of attachment loss observed from clinical and radiographic examination. No evidence of diabetes mellitus, stroke, or other severe systemic diseases was found in these patients.

Periodontitis and CHD group (Perio + CHD) Nineteen subjects (six females, 13 males; age, 45-55 years) with proven CHD and periodontitis according the criteria for groups Perio and CHD.

Healthy control (Control) Twenty-four subjects (14 females, 10 males; age, 22-53 years) with no clinical or radiographic evidence of periodontal or systemic diseases.

In the groups Perio and Control, no participant had a history of systemic diseases according to their self-reported medical history, received antibiotics or other medication, or periodontal treatment within the past 4 weeks.

\section{Clinical examination}

All subjects underwent a comprehensive clinical periodontal examination. At six sites of each existing tooth probing depth (PD), clinical attachment level (CAL), bleeding on 
probing (BOP), sulfide levels (SUL), and plaque index (PLI) were recorded. BOP was recorded $20 \mathrm{~s}$ after gentle probing. Sulfide levels were measured using the Diamond Probe/Perio 2000 system (Diamond General Development Corp., USA). The system is a dental device designed to detect sulfide concentrations of various forms $\left(\mathrm{S}, \mathrm{HS}, \mathrm{H}_{2} \mathrm{~S}\right.$, and $\mathrm{CH}_{3} \mathrm{SH}$ ) within the gingival sulcus [21] and combines a conventional Michigan "O" style dental probe with a sulfide sensor. Radiographs were obtained to determine any radiographic bone loss.

\section{Sampling of GCF and serum}

GCF samples were collected with filter paper as previously described [22]. For the groups Perio and Perio + CHD, the GCF samples were collected from the four deepest sites in each quadrant. For the groups CHD and Control, the GCF samples were collected from the mesiobuccal surfaces of the first molar in each quadrant. If the first molar was absent, the second molar was sampled. Prior to GCF sampling, the tooth surfaces were dried gently by an air syringe and were isolated by cotton rolls. Supragingival plaque was gently removed. Paper strips were carefully inserted into the crevice until mild resistance was felt and were left in place for $30 \mathrm{~s}$. Care was taken to avoid mechanical injury. Strips contaminated with blood were discarded. Papers were weighed before and after sampling to calculate the mass of the GCF sample. The strips were separately placed into a $1.5 \mathrm{ml}$ Eppendorf tube and kept at $-20 \mathrm{C}^{\circ}$ until analysis.

At the same time $3 \mathrm{ml}$ venous blood was sampled from the cubital vein of each subject. The whole blood samples were centrifuged (2,000 ppm for $2 \mathrm{~min})$, and serum was stored at $-70 \mathrm{C}^{\circ}$ in Eppendorf tubes until future processing.

\section{Laboratory assays}

The quantitative measurement of PAF in serum and GCF was performed using an enzyme-linked immunosorbent assay (Human Serum PAF Assay Kit, TPI Inc., USA). Each GCF sample was analyzed separately by soaking the filter paper in
$1 \mathrm{ml}$ diluent solution to elute PAF. All procedures were performed according to the manufacturer's instructions, and GCF and serum samples were assayed in duplicate.

\section{Statistical analysis}

For all parameters, means and standard deviations were calculated using the individual subject as the statistical unit. Differences between the four investigated groups with respect to the periodontal parameters and PAF levels in GCF and serum were tested for statistical significance using the Kruskal-Wallis Test. In case of a significant difference, a 2-group comparison was conducted using a post hoc test. A value of $p<0.05$ was considered as statistically significant. To analyze the correlations between PAF levels and periodontal parameters, the patients were the statistical unit, and Spearman rank correlation analysis was performed. All statistical analyses were performed using the SAS statistical software package.

\section{Results}

\section{Periodontal parameters}

The mean values for the clinical parameters in each group are presented in Table 2. For all periodontal parameters, no significant differences were found between the Perio + CHD and the Perio groups. The mean values for PD and CAL in the Perio + CHD and the Perio group were significantly higher than the values in the CHD group and the healthy control group $(p<0.001)$. The mean PD in the CHD group was slightly higher compared to the healthy controls.

The bleeding scores in Perio + CHD group were significantly higher than the scores in the CHD group ( $p=$ $0.006)$ and the healthy control group $(p<0.001)$. BOP in the Perio group was significantly different compared to the BOP scores of the CHD group $(p=0.001)$ and the control group $(p<0.001)$. Statistically significant differences were also observed for BOP between the CHD group and the healthy control group $(p<0.001)$.

Table 2 Mean values and standard deviation for oral clinical parameters of the investigated groups

\begin{tabular}{|c|c|c|c|c|c|c|c|c|c|c|c|}
\hline \multirow[t]{2}{*}{ Group } & \multirow[t]{2}{*}{ Number } & \multicolumn{2}{|c|}{$\mathrm{PD}(\mathrm{mm})$} & \multicolumn{2}{|c|}{ CAL (mm) } & \multicolumn{2}{|c|}{ BOP (\%) } & \multicolumn{2}{|l|}{ PLI } & \multicolumn{2}{|c|}{ SUL (\%) } \\
\hline & & Mean & SD & Mean & SD & Mean & $\mathrm{SD}$ & Mean & SD & Mean & SD \\
\hline Perio+CHD & 19 & 4.82 & $0.57^{\mathrm{a}, \mathrm{b}}$ & 5.68 & $1.89^{\mathrm{a}, \mathrm{b}}$ & 62.95 & $16.10^{\mathrm{a}, \mathrm{b}}$ & 2.75 & $0.18^{\mathrm{a}}$ & 26.99 & $8.30^{\mathrm{a}}$ \\
\hline Perio & 25 & 4.61 & $0.80^{\mathrm{a}, \mathrm{b}}$ & 5.98 & $1.29^{\mathrm{a}, \mathrm{b}}$ & 59.78 & $19.41^{\mathrm{a}, \mathrm{b}}$ & 2.76 & $0.17^{\mathrm{a}}$ & 28.03 & $8.44^{\mathrm{a}}$ \\
\hline CHD & 19 & 2.52 & 0.46 & 0.00 & 0.00 & 42.65 & $18.89^{\mathrm{a}}$ & 2.61 & $0.38^{\mathrm{a}}$ & 21.72 & $8.00^{\mathrm{a}}$ \\
\hline Healthy & 24 & 2.16 & 0.26 & 0.00 & 0.00 & 7.09 & 6.70 & 1.42 & 0.68 & 5.98 & 5.50 \\
\hline
\end{tabular}

${ }^{\text {a }}$ Statistically significant difference to the healthy controls (Kruskal-Wallis Test followed by post hoc test $(p<0.05)$

${ }^{\mathrm{b}}$ Statistically significant difference to group CHD (Kruskal-Wallis test followed by post hoc test; $p<0.05$ ) 
In all patient groups, the PLI was significantly different from the PLI in the healthy control group $(p<0.001)$. No statistically significant differences were observed between the PLI scores of Perio + CHD group, Perio group, and CHD group $(p=0.589)$.

All patient groups showed significantly higher SUL levels than the healthy controls $(p<0.001)$. No significant difference was observed of SUL levels between Perio + CHD and CHD groups $(p=0.283)$ or between Perio and CHD group $(p=0.090)$.

PAF levels in serum

The levels of PAF in GCF and serum of the four groups under investigation are shown in Table 3 . The data show significant differences of serum PAF levels between Perio + CHD, Perio, and CHD groups compared to the healthy controls $(p<0.001)$. No significant differences were observed between the three patient groups.

\section{PAF levels in GCF}

Values for the total amount of PAF per sample (pg/sample) and for the PAF concentration $(\mathrm{pg} / \mu \mathrm{l})$ are presented in Table 3 . All patient groups showed significantly higher PAF levels in GCF on a per sample and on a concentration basis compared to the Control group $(p<0.001)$. No significant differences of PAF levels in GCF were calculated between Perio + CHD and Perio group. The PAF levels in GCF for Perio + CHD group and Perio group were significantly higher $(p=0.002$ and $p<0.001$, respectively) compared to CHD group. On a concentration basis, the PAF levels in the GCF of Perio + CHD group were significantly different from the PAF levels of the CHD group $(p=0.039)$. No significant difference between Perio and CHD group were observed $(p=0.051)$.

\section{PAF levels in GCF compared to serum}

The results of the Spearman correlation analysis are presented in Fig. 1. A significant positive correlation was observed for all three patients groups for the PAF concentration in serum and the total amount of PAF in GCF $(r=0.748, p<0.001)$ and for the concentration of PAF in GCF $(r=0.784, p<0.001)$. For the CHD group, the PAF levels in serum $(\mathrm{pg} / \mathrm{ml})$ and in GCF (pg/ $\mu$ l and $\mathrm{pg} / \mathrm{sample})$, a significant positive correlation was found $(r=0.927, p<$ 0.001 and $r=0.883, p<0.001$, respectively), as well as for the Perio group $(r=0.807, p<0.001$ and $r=0.787, p<0.001$, respectively) and for the Perio + CHD group $(r=0.930, p<$ 0.001 and $r=0.880, p<0.001$, respectively). In healthy individuals, the PAF levels in serum and GCF showed only low correlations ( $r=0.558, p<0.001$ and $r=0.452, p=0.005$, respectively).

\section{Periodontal parameters compared to PAF levels}

For the Perio group, a significant correlation between the periodontal parameter PD and the PAF levels in serum $(r=$ $0.732, p<0.001)$ and GCF $(r=0.792, p<0.001)$ was observed. For the parameter BOP, a correlation with serum PAF levels of $r=0.609(p<0.001)$ and with GCF PAF levels (pg/ sample) of $r=0.488(p=0.001)$ was calculated. For the CHD group, a significant correlation between PD and serum PAF levels $(r=0.692, p<0.001)$ or GCF PAF levels $(r=0.752, p<$ $0.001)$ was observed. For the parameter BOP, a correlation with serum PAF levels of $r=0.836(p<0.001)$ and with GCF PAF levels (pg/sample) of $r=0.743(p=0.001)$ was calculated for this group. For the patients suffering from periodontitis and coronary heart disease (Perio + CHD group), a significant positive correlation was observed between the serum PAF levels $(\mathrm{pg} / \mathrm{ml})$ and the clinical parameter PD $(r=$ $0.845, p<0.001)$, CAL $(r=0.751, p<0.001)$, and PLI $(r=$ $0.840, p<0.001)$. These patients also showed a significant correlation between the GCF PAF levels (pg/sample) and the clinical parameter PD $(r=0.0 .798, p<0.001)$, CAL $(r=0.751$, $p<0.001)$, and PLI $(r=0.803, p<0.001)$. The Perio + CHD group showed, for the parameter BOP, a correlation with serum PAF levels of $r=0.563(p=0.001)$ and with GCF PAF levels (pg/sample) of $r=0.540(p=0.001)$. In healthy subjects, all clinical periodontal parameters showed low correlations with the PAF levels in serum (pg/ml) and in GCF (pg/ sample; data not presented).

Table 3 Mean values of PAF in GCF and serum for the investigated patient groups and healthy controls

\begin{tabular}{|c|c|c|c|c|c|c|c|c|}
\hline & \multicolumn{2}{|c|}{ Perio+CHD } & \multicolumn{2}{|l|}{ Perio } & \multicolumn{2}{|l|}{$\mathrm{CHD}$} & \multicolumn{2}{|c|}{ Healthy } \\
\hline & Mean & SD & Mean & SD & Mean & SD & Mean & SD \\
\hline PAF in serum $(\mathrm{pg} / \mathrm{ml})$ & 303.33 & $204.92^{\mathrm{a}}$ & 302.37 & $240.58^{\mathrm{a}}$ & $284.71^{\mathrm{a}}$ & $192.40^{\mathrm{a}}$ & 65.38 & 34.85 \\
\hline PAF in (pg/sample) & 21.41 & $6.50^{\mathrm{a}, \mathrm{b}}$ & 21.35 & $5.87^{\mathrm{a}, \mathrm{b}}$ & 14.59 & $3.14^{\mathrm{a}}$ & 2.96 & 2.80 \\
\hline PAF in GCF $(\mathrm{pg} / \mu \mathrm{l})$ & 26.33 & $6.11^{\mathrm{a}, \mathrm{b}}$ & 26.31 & $7.49^{\mathrm{a}}$ & 20.83 & $5.63^{\mathrm{a}}$ & 7.66 & 3.52 \\
\hline
\end{tabular}

${ }^{a}$ Statistically significant difference to the healthy controls (Kruskal-Wallis Test followed by post hoc test; $p<0.05$ )

${ }^{\mathrm{b}}$ Statistically significant difference to group CHD (Kruskal-Wallis Test followed by post hoc test; $p<0.05$ ) 
a
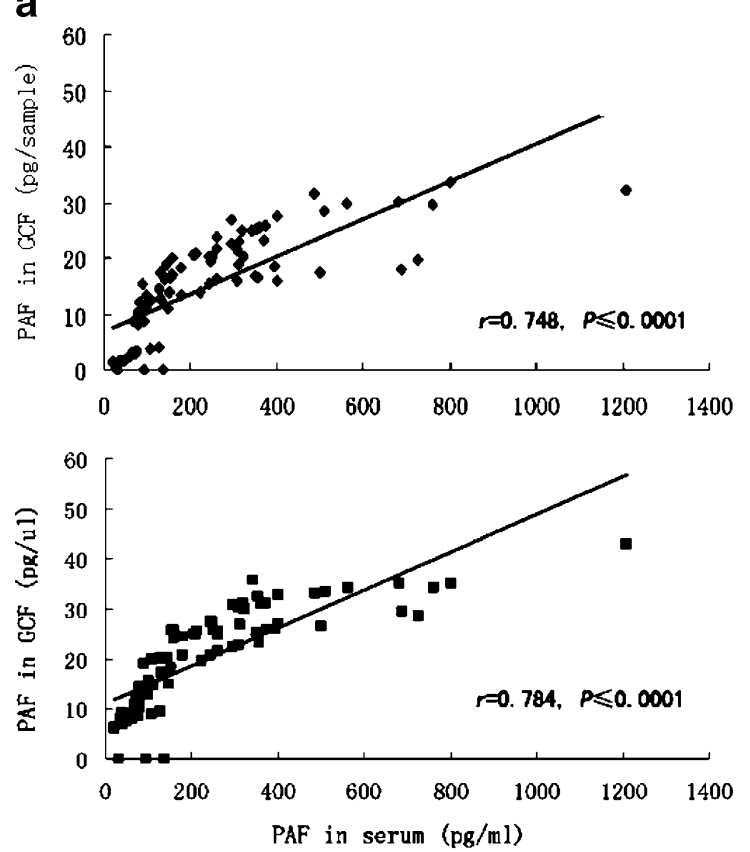

C
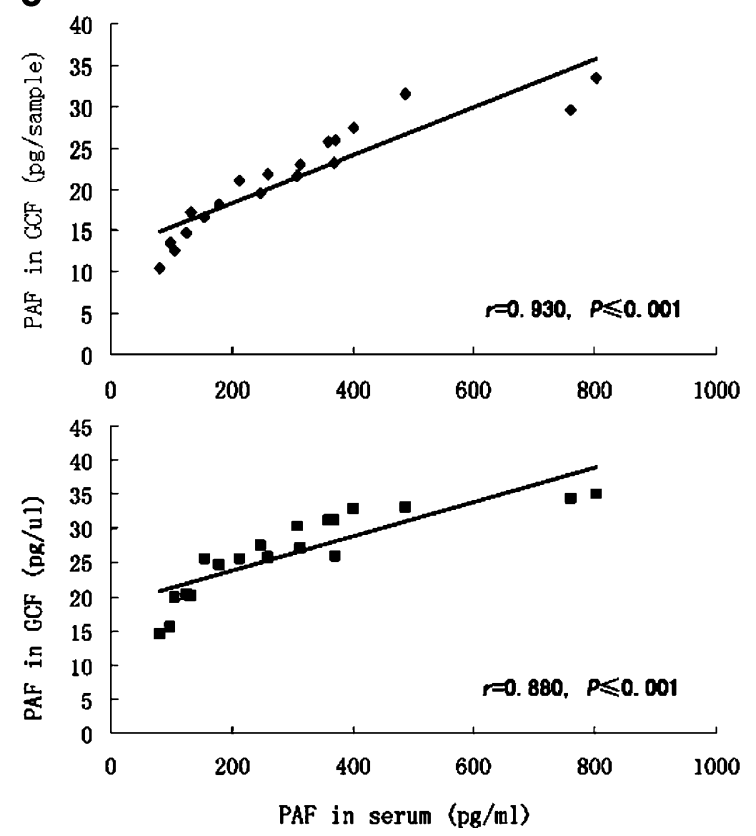

b
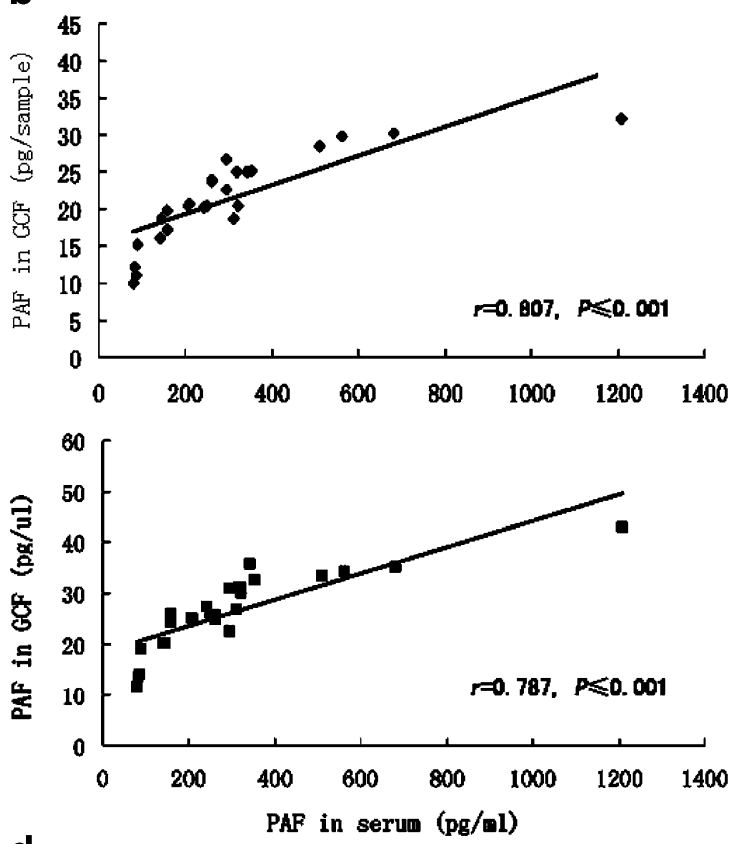

d
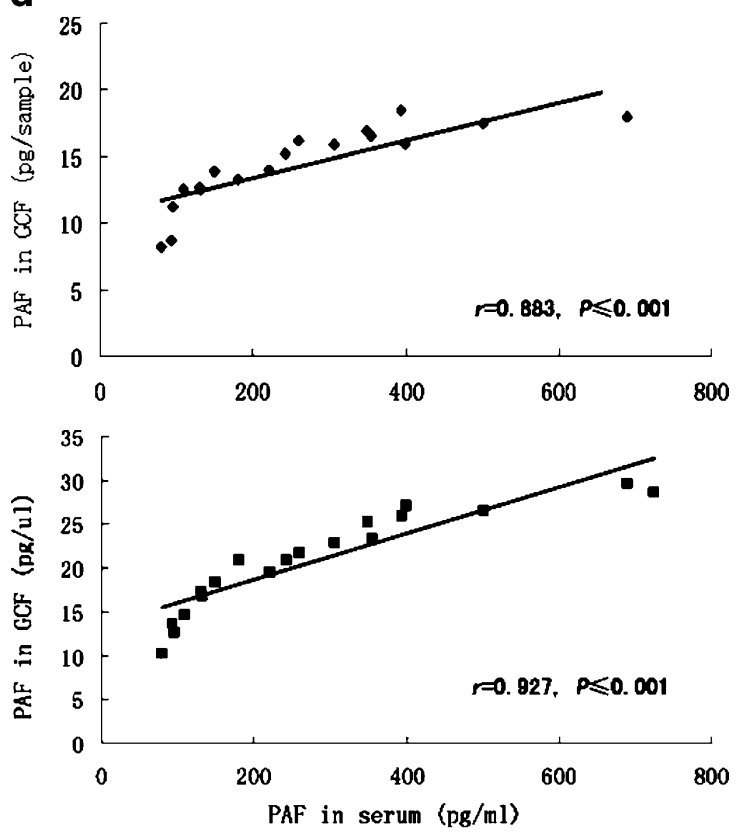

Fig. 1 Correlation analysis between the PAF levels in serum (pg/ml) and GCF (pg/sample; pg/ul) for a all patients groups, b the Perio group, c Perio + CHD group, and $\mathbf{d}$ the CHD group

\section{Discussion}

Atherosclerosis, with its major manifestation of coronary artery disease, remains a major cause of mortality in western populations, and epidemiological studies have identified several risk factors such as smoking, diabetes mellitus, hypertension, and dyslipidemia in the etiology of atherosclerosis [1]. Recently, studies have indicated that periodontitis may lead to alterations in systemic health [23] and may influence the occurrence and the severity of coronary artery disease [24-26]. However, whether periodontal infections play a causal role in the occurrence of coronary artery disease is still debated [27].

Two hypothetical pathways could be considered for the systemic effects of periodontal infections. One hypothesis is that periodontal pathogens could enter the bloodstream and have atherogenic effects. The direct invasion of blood vessel and atherosclerotic plaques by periodontal pathogens has been described [28]. In fact, recently, a broad variety of molecular signatures from a diverse bacterial colonization 
was found in atherosclerotic coronary specimens [29]. Another hypothesis raised by several studies is based on elevated levels of inflammatory mediators circulating in the bloodstream. Cross-sectional and prospective studies have established that elevated peripheral blood levels of several systemic inflammatory markers including $\mathrm{C}$-reactive protein, fibrinogen, PAF, and the cytokines IL- $1 \beta$ and IL- 6 and TNF-alpha are associated with the risk of cardiovascular diseases and the severity of atherosclerosis [15, 30-33]. It has been proposed that these mediators are elevated during periodontal infection and their proinflammatory properties may subsequently increase the existing inflammatory activity in plaque-associated lesions in coronary arteries. Therefore, a systemic elevation of the concentration of an inflammatory mediator like PAF released from periodontitis-affected tissues could explain at least in part the observed association of periodontitis with cardiovascular disease.

As a potent phospholipid mediator of inflammatory and immune reactions, PAF contributes to numerous pathologic reactions in vivo. PAF activates neutrophils and causes chemotaxis aggregation, superoxide generation, and degranulation. PAF synthesized by endothelial cells and exposed on the cell surface may, together with $\mathrm{P}$ selectin, promote leukocyte adhesion to endothelial cells [34]. This interaction may be important for the activation and the subsequent infiltration of monocytes-macrophages, the production of proliferative cytokines, and accumulation of lipids within the cells and in consequence, for the biological role of PAF in atherosclerosis $[13,35]$. The role of PAF in ischemia and reperfusion injury of the heart is supported by clinical experiments [36]. Moreover, cigarette smoking associated with the pathogenesis of atherosclerosis causes platelet activation, LDL oxidative changes, and increased levels of PAF [37].

In the present study, PAF levels in serum and gingival crevicular fluid from patients with periodontitis, periodontitis and coronary heart disease, and coronary heart diseases were compared to healthy subjects. To our knowledge, this is the first report of PAF levels in serum and GCF from these distinct patients groups and healthy controls. The interpretation of the results is limited by the fact that information of systemic and general health characteristics is not completely available for the present study population and in consequence, other traditional risk factors for cardiovascular diseases were not included in the analysis. However, all participants were nonsmokers, and smoking is a well-established risk factor for cardiovascular diseases [1]. It would be, of course, of interest to know all other kinds of infections or inflammatory processes of the participants that may increase serum PAF levels. For patients suffering from periodontitis or CHD, elevated levels of PAF were found in serum in comparison to healthy controls; however, the concurrent diagnosis of periodontitis and CHD did not show significant changes in the systemic levels of PAF. In a study of glomerulonephritis, whole blood PAF levels in healthy individuals of approximately $0.5 \mathrm{pg} / \mathrm{ml}$ and $1.0 \mathrm{pg} / \mathrm{ml}$ for patients suffering from glomerulonephritis have been reported [38]. However, comparison of these values is limited by different analyzing methods and the detection in whole blood or in serum.

It is interesting to see that the PAF levels from patients with periodontitis, patients with periodontitis and CHD, and patients exclusively with CHD did not show significant differences of the serum PAF levels. A similar observation was also documented in two studies measuring C-reactive protein (CRP) in patients with periodontitis and patients who developed cardiovascular events [39, 40]. For patients with generalized periodontitis, a median value for CRP of $1.90 \mathrm{mg} / \mathrm{L}$ was reported, which was in a similar range measured for men who developed cardiovascular events with median baseline CRP levels of 1.26 to $1.51 \mathrm{mg} / \mathrm{l}$. These data are in agreement with the results of the present study demonstrating similar systemic levels of inflammatory mediators irrespective of the origin of the tissues involved in the inflammatory process. However, the underlying systemic regulatory mechanisms for the described observations are not clear. PAF released from atherosclerotic plaques or periodontal tissues into venous capillaries is exposed to several regulatory mechanisms, and biochemical processes during passage of the arterial system and capillary tissues before it reaches the venous system of the arm where the sample is collected. For example, a key mechanism for the removal of PAF in blood is hydrolysis catalyzed by PAF acetylhydrolase (PAF-AH), which converts PAF to the biologically inactive lyso-PAF [41]. The removal from the circulation by degradation, as well as the local production of PAF by inflammatory cells in the inflamed periodontal and gingival tissues can explain the observed differences of PAF concentrations in GCF compared to serum.

When measuring the inflammatory mediator PAF in GCF proximal to the inflammatory reaction of the periodontal tissues, the PAF levels in GCF were found to be significantly elevated for patients suffering from periodontitis and patients suffering from periodontitis and CHD compared to patients with CHD. In contrast to serum levels, this observation showed the additional effect of the systemic levels and the local PAF levels in GCF from periodontitis. This observation was found on per sample base, but not for concentrations. However, the expression of metabolites in GCF as a total amount per standardized sampling time is a more sensitive way than reporting them as concentrations [42]. In a study of Turkish patients suffering from chronic periodontitis, PAF levels of 
$194.11 \mathrm{pg} / \mu \mathrm{l}$ in GCF and from healthy individuals, PAF levels of approximately $15 \mathrm{pg} / \mu \mathrm{l}$ were measured after HPLC extraction and radioimmunoassay-based quantification [18]. In a study initiated to study the PAF concentration in GCF by HPLC, approximately $470 \mathrm{ng} / \mathrm{ml}$ PAF was found in the GCF before periodontal treatment, which was in contrast to the $56 \mathrm{ng} / \mathrm{ml}$ PAF found 24 weeks after periodontal therapy [43]. The observed differences between these studies may originate from different sampling and analyzing methods. In addition, it has been shown that initial periodontal therapy (home care instruction, prophylaxis, and scaling/root planing) can reduce salivary PAF levels in concert with improvements in clinical parameters of periodontal inflammation [44]. Salivary PAF most likely originates from the crevicular space and derives from inflammatory cells within the gingival and/or periodontal tissues [45].

In conclusion, these data and the correlation analysis between GCF and serum levels verified that PAF is released from periodontitis affected tissues into GCF and contributes to increased serum levels of the mediator measured in periodontitis patients.

The PAF levels in both serum and GCF of all patients had significantly positive correlations with all periodontal parameters and they increased with the severity of the periodontal inflammation and destruction. These observations showed that the elevated PAF levels in GCF and serum were from the inflammatory process of the periodontal tissues and that this mediator plays a pivotal role in the inflammatory process of the periodontal tissues. The results confirmed recently published data for patients suffering from periodontitis [20]. Surprisingly, the clinical inflammatory marker BOP was less correlated with the PAF levels in serum from patients suffering from periodontitis than from patients with CHD. Although, CHD patients showed PD levels in the range of the healthy controls, they demonstrated increased plaque levels resulting in increased bleeding tendency indicating that the CHD patients suffered from gingivitis. The slightly higher probing depths were most likely due to gingival swelling. It could be speculated that the elevated levels of PAF in serum and GCF resulted from the inflammatory processes of the endothelium, and may have decreased the antibacterial immune response of the gingival tissues following increased accumulation of plaque. Reduced oral hygiene could also be a factor associated with a low socioeconomic status of the patients, which is a risk factor for coronary heart diseases [46]. In our previous work [20], in different patients, we could establish serum and GCF PAF levels in patients with periodontitis, gingivitis, and in healthy controls. All values for the periodontitis group and the healthy controls were very similar to our present findings and could, thus, be confirmed. In contrast, the gingivitis group in the previous study demonstrated similar GCF values but lower serum
PAF levels $(138 \pm 77 \mathrm{pg} / \mathrm{ml})$ compared to the CHD group $(284 \pm 192 \mathrm{pg} / \mathrm{ml})$ in the present study. We interpret these data-derived from a "historical" control group -as an indication that at least part of the elevated serum PAF in the patients with CHD has to be attributed to their systemic condition. Unfortunately, for the present study, it was not possible to recruit CHD patients without any signs of gingival inflammation. Therefore, the relative contribution of CHD and gingivitis on elevated serum PAF levels could not be determined more precisely.

Taken together, our data provide evidence that the inflammatory mediator PAF is released from periodontitisaffected tissues into serum at least in the same range as the PAF levels measured for patients with coronary heart disease. However, no additive effects were seen when both conditions were present.

Acknowledgement This work was funded by the Science and Technology Department of Zhejiang Province 2004c34011 and partially supported by scholarships from the Deutscher Akademischer Austausch Dienst (DAAD).

Conflict of interest The authors declare that they have no conflict of interest.

\section{References}

1. Wu LL (1999) Review of risk factors for cardiovascular diseases. Ann Clin Lab Sci 29:127-133

2. Mehta JL, Saldeen TG, Rand K (1998) Interactive role of infection, inflammation and traditional risk factors in atherosclerosis and coronary artery disease. J Am Coll Cardiol 31:1217-1225

3. Leinonen M, Saikku P (2002) Evidence for infectious agents in cardiovascular disease and atherosclerosis. Lancet Infect Dis 2:11-17

4. Scannapieco FA, Genco RJ (1999) Association of periodontal infections with atherosclerotic and pulmonary diseases. J Periodontal Res 34:340-345

5. Noack B, Genco RJ, Trevisan M, Grossi S, Zambon JJ, De Nardin E (2001) Periodontal infections contribute to elevated systemic Creactive protein level. J Periodontol 72:1221-1227

6. Geerts SO, Legrand V, Charpentier J, Albert A, Rompen EH (2004) Further evidence of the association between periodontal conditions and coronary artery disease. J Periodontol 75:1274-1280

7. Montebugnoli L, Servidio D, Miaton RA, Prati C, Tricoci P, Melloni C (2004) Poor oral health is associated with coronary heart disease and elevated systemic inflammatory and haemostatic factors. J Clin Periodontol 31:25-29

8. Danesh J, Collins R, Peto R (1997) Chronic infections and coronary heart disease: is there a link? Lancet 350:430-436

9. Prescott SM, Zimmerman GA, Stafforini DM, McIntyre TM (2000) Platelet-activating factor and related lipid mediators. Annu Rev Biochem 69:419-445

10. Stafforini DM, McIntyre TM, Zimmerman GA, Prescott SM (2003) Platelet-activating factor, a pleiotrophic mediator of physiological and pathological processes. Crit Rev Clin Lab Sci 40:643-672

11. Behrens TW, Goodwin JS (1990) Control of human T cell proliferation by platelet-activating factor. Int J Immunopharmacol $12: 175-184$ 
12. Denizot Y, Dupuis F, Praloran V (1994) Effects of plateletactivating factor on human $\mathrm{T}$ and $\mathrm{B}$ cells - an overview. Res Immunol 145:109-116

13. Ninio E (2005) Phospholipid mediators in the vessel wall: involvement in atherosclerosis. Curr Opin Clin Nutr Metab Care 8:123-131

14. Ghesquiere SA, Hofker MH, de Winther MP (2005) The role of phospholipases in lipid modification and atherosclerosis. Cardiovasc Toxicol 5:161-182

15. Subbanagounder G, Leitinger N, Shih PT, Faull KF, Berliner JA (1999) Evidence that phospholipid oxidation products and/or platelet-activating factor play an important role in early atherogenesis: in vitro and in vivo inhibition by WEB 2086. Circ Res $85: 311-318$

16. Mueller HW, Haught CA, McNatt JM, Cui K, Gaskell SJ, Johnston DA, Willerson JT (1995) Measurement of plateletactivating factor in a canine model of coronary thrombosis and in endarterectomy samples from patients with advanced coronary artery disease. Circ Res 77:54-63

17. Cox CP, Wardlow ML, Jorgensen R, Farr RS (1981) The presence of platelet-activating factor (PAF) in normal human mixed saliva. J Immunol 127:46-50

18. Emingil G, Cinarcik S, Baylas H, Huseyinov A (2001) Levels of platelet-activating factor in gingival crevicular fluid and gingival tissue in specific periodontal diseases. J Periodontol 72:10321037

19. Keles GC, Cetinkaya BO, Ayas B, Isildak I, Diraman E, Koprulu H, Acikgoz G (2007) Levels of gingival tissue platelet activating factor after conventional and regenerative periodontal surgery. Clin Oral Investig 11:369-376

20. Zheng P, Chen H, Shi S, Jepsen S, Eberhard J (2006) Periodontal parameters and platelet-activating factor levels in serum and gingival crevicular fluid in a Chinese population. J Clin Periodontol 33:797-802

21. Zhou H, McCombs GB, Darby ML, Marinak K (2004) Sulphur by-product: the relationship between volatile sulphur compounds and dental plaque-induced gingivitis. J Contemp Dent Pract 5: 27-39

22. Lamster IB, Oshrain RL, Celenti R, Levine K, Fine JB (1991) Correlation analysis for clinical and gingival crevicular fluid parameters at anatomically related gingival sites. J Clin Periodontol 18:272-277

23. Iacopino AM, Cutler CW (2000) Pathophysiological relationships between periodontitis and systemic disease: recent concepts involving serum lipids. J Periodontol 71:1375-1384

24. Cutler CW, Shinedling EA, Nunn M, Jotwani R, Kim BO, Nares S, Iacopino AM (1999) Association between periodontitis and hyperlipidemia: cause or effect? J Periodontol 70:1429-1434

25. Beck J, Garcia R, Heiss G, Vokonas PS, Offenbacher S (1996) Periodontal disease and cardiovascular disease. J Periodontol 67:1123-1137

26. Arbes SJ Jr, Slade GD, Beck JD (1999) Association between extent of periodontal attachment loss and self-reported history of heart attack: an analysis of NHANES III data. J Dent Res 78:1777-1782

27. Mattila KJ, Asikainen S, Wolf J, Jousimies-Somer H, Valtonen V, Nieminen M (2000) Age, dental infections, and coronary heart disease. J Dent Res 79:756-760

28. Haraszthy VI, Zambon JJ, Trevisan M, Zeid M, Genco RJ (2000) Identification of periodontal pathogens in atheromatous plaques. $\mathrm{J}$ Periodontol 71:1554-1560

29. Ott SJ, El Mokhtari NE, Musfeldt M, Hellmig S, Freitag S, Rehman A, Kuhbacher T, Nikolaus S, Namsolleck P, Blaut M,
Hampe J, Sahly H, Reinecke A, Haake N, Gunther R, Kruger D, Lins M, Herrmann G, Folsch UR, Simon R, Schreiber S (2006) Detection of diverse bacterial signatures in atherosclerotic lesions of patients with coronary heart disease. Circulation 113:929-937

30. Biasucci LM, Vitelli A, Liuzzo G, Altamura S, Caligiuri G, Monaco C, Rebuzzi AG, Ciliberto G, Maseri A (1996) Elevated levels of interleukin-6 in unstable angina. Circulation 94:874-877

31. Ridker PM, Buring JE, Shih J, Matias M, Hennekens CH (1998) Prospective study of C-reactive protein and the risk of future cardiovascular events among apparently healthy women. Circulation 98:731-733

32. Berk BC, Weintraub WS, Alexander RW (1990) Elevation of Creactive protein in "active" coronary artery disease. Am J Cardiol $65: 168-172$

33. Loos BG, Craandijk J, Hoek FJ, Wertheim-van Dillen PM, van der Velden U (2000) Elevation of systemic markers related to cardiovascular diseases in the peripheral blood of periodontitis patients. J Periodontol 71:1528-1534

34. Zimmerman GA, Prescott SM, McIntyre TM (1992) Endothelial cell interactions with granulocytes: tethering and signaling molecules. Immunol Today 13:93-100

35. Montrucchio G, Alloatti G, Camussi G (2000) Role of plateletactivating factor in cardiovascular pathophysiology. Physiol Rev 80:1669-1699

36. Montrucchio G, Camussi G, Tetta C, Emanuelli G, Orzan F, Libero L, Brusca A (1986) Intravascular release of plateletactivating factor during atrial pacing. Lancet 2:293

37. Miyaura S, Eguchi H, Johnston JM (1992) Effect of a cigarette smoke extract on the metabolism of the proinflammatory autacoid, platelet-activating factor. Circ Res 70:341-347

38. Iatrou C, Moustakas G, Antonopoulou S, Demopoulos CA, Ziroyiannis P (1996) Platelet-activating factor levels and PAF acetylhydrolase activities in patients with primary glomerulonephritis. Nephron 72:611-616

39. D'Aiuto F, Parkar M, Andreou G, Suvan J, Brett PM, Ready D, Tonetti MS (2004) Periodontitis and systemic inflammation: control of the local infection is associated with a reduction in serum inflammatory markers. J Dent Res 83:156-160

40. Ridker PM, Cushman M, Stampfer MJ, Tracy RP, Hennekens CH (1997) Inflammation, aspirin, and the risk of cardiovascular disease in apparently healthy men. N Engl J Med 336:973-979

41. Stafforini DM, Prescott SM, Zimmerman GA, McIntyre TM (1996) Mammalian platelet-activating factor acetylhydrolases. Biochim Biophys Acta 1301:161-173

42. Lamster IB, Oshrain RL, Gordon JM (1986) Enzyme activity in human gingival crevicular fluid: considerations in data reporting based on analysis of individual crevicular sites. J Clin Periodontol 13:799-804

43. Keles GC, Cetinkaya BO, Isildak I, Koprulu H, Acikgoz G (2006) Levels of platelet activating factor in gingival crevice fluid following periodontal surgical therapy. J Periodontal Res 41:513-518

44. Rasch MS, Mealey BL, Prihoda TJ, Woodard DS, McManus LM (1995) The effect of initial periodontal therapy on salivary platelet-activating factor levels in chronic adult periodontitis. $\mathrm{J}$ Periodontol 66:613-623

45. McManus LM, Marze BT, Schiess AV (1990) Deficiency of salivary PAF in edentulous individuals. J Periodontal Res 25:347-351

46. Yarnell J, Yu S, McCrum E, Arveiler D, Hass B, Dallongeville J, Montaye M, Amouyel P, Ferrieres J, Ruidavets JB, Evans A, Bingham A, Ducimetiere P (2005) Education, socioeconomic and lifestyle factors, and risk of coronary heart disease: the PRIME Study. Int J Epidemiol 34:268-275 